\title{
ACORDOS COMERCIAIS E O SETOR PRODUTIVO DE CARNE BOVINA: ESTIMATIVAS DE GANHOS PARA O MERCOSUL
}

\author{
Paulo D. Waquil ${ }^{1}$ \\ Augusto M. Alvim ${ }^{2}$
}

\begin{abstract}
Resumo - Este estudo identifica os efeitos de acordos de livre comércio, de caráter multilateral (no âmbito da OMC) e regional (ALCA e MERCOSUL-UE), sobre os mercados de carne bovina nas diversas regiões analisadas. Para avaliar os efeitos destas negociações, utilizou-se um modelo de alocação espacial, apresentado como um Problema de Complementaridade Mista (PCM). Como resultados, este estudo identificou as variações nos níveis de produção e consumo, assim como as variações nos excedentes do produtor e do consumidor, em quatro possíveis cenários. Em termos gerais, houve ganhos para os produtores de carne bovina, nos países do MERCOSUL, em todos os cenários. No entanto, estes ganhos foram maiores quando simulada a liberalização de mercados no âmbito multilateral, com eliminação ou não dos subsídios.
\end{abstract}

Palavras-chaves: Livre comércio, integração regional, problema de complementaridade mista, carne bovina.

\section{Introdução}

O mercado internacional de carne bovina caracteriza-se pela concentração da produção, do consumo e dos fluxos comerciais em número reduzido de países. De um total de 206 países listados na base de dados da Food and Agriculture Organization (FAO), apenas 5 são responsáveis por mais da metade da produção e do consumo de carne bovina. Conforme dados mais recentes disponibilizados pela FAO, entre

Doutor em Economia Agrícola. Professor do Departamento de Economia (DECON) e dos Programas de PósGraduação em Desenvolvimento Rural (PGDR) e Agronegócios (PPGAN) da Universidade Federal do Rio Grande do Sul (UFRGS). E-mail: waquil@ufrgs.br

2 Doutor em Economia. Professor do Departamento de Ciências Econômicas da Pontifícia Universidade Católica do Rio Grande do Sul (PUC-RS). E-mail: augusto.alvim@pucrs.br 
os principais produtores em 2004, destacam-se os Estados Unidos (EUA, com 19,0\% do total), Brasil (13,1\%), China (11,0\%), Argentina (4,6\%) e Austrália (3,4\%).

Entretanto, os maiores exportadores e importadores de carne bovina não são exatamente aos países que possuem maior participação na produção e no consumo. A base de dados da FAO aponta um total de 162 países exportadores de carne bovina, mas, novamente, apenas cinco são responsáveis por mais da metade do total comercializado internacionalmente. Entre os maiores exportadores em 2003 (dados disponíveis no momento), estão Austrália (14,3\% do total), EUA (13,7\%, apesar de ser também o maior importador de carne bovina), Brasil (12,8\%), Alemanha $(5,5 \%)$ e Canadá (4,6\%). O Brasil vem, ao longo dos últimos anos, aumentando sua participação na produção e nas exportações e, em 2005, já apareceu como o maior exportador de carne bovina, de acordo com informações do Anuário Brasileiro da Pecuária. Entretanto, entre os principais importadores estão, além dos EUA, o Japão, a Rússia e alguns países da União Européia.

A conformação do mercado internacional de carne bovina deve-se, em parte, às vantagens competitivas das regiões envolvidas, análise que foi bem desenvolvida no trabalho de Rubin (2005), mas também aos diversos tipos de barreiras comerciais impostas pelas regiões envolvidas. Além de restringirem o comércio, tais barreiras podem redirecionar os fluxos, o que ocasiona desvios de comércio.

Entre as principais barreiras comerciais existentes no mercado internacional de carne bovina, destacam-se as medidas que influenciam o acesso aos mercados, como as barreiras tarifárias (tarifas e quotastarifárias) e as não-tarifárias (sanitárias e técnicas), assim como os subsídios concedidos à produção e à exportação.

Com relação às barreiras tarifárias, os países em desenvolvimento são os que impõem as maiores tarifas, a exemplo da China e do Brasil (neste caso, a Tarifa Externa Comum do MERCOSUL), que impõem tarifas de $25 \%$ e $11,5 \%$, respectivamente; no entanto, países (ou blocos) 
desenvolvidos como EUA, UE, Rússia e Japão (importadores), em geral, não aplicam barreiras tarifárias sobre as importações de carne bovina (UNCTAD, 2005), mas impõem outras medidas restritivas, como barreiras técnicas e sanitárias. As barreiras técnicas impedem a importação de produtos segundo critérios, padrões e normas de inspeção, que compreendem aspectos relativos a segurança, embalagem, procedência do produto e conteúdo tecnológico do produto. Já as medidas sanitárias são mais específicas e incluem aspectos ligados à sanidade animal (Miranda, 2001).

Por último, os subsídios à produção e à exportação são determinantes das maiores distorções nos preços internacionais. A exemplo disto, os EUA e a UE são responsáveis pelas maiores concessões de recursos para produção e exportação de carne bovina; em contrapartida, a maioria dos produtores dos países em desenvolvimento não dispõe de recursos subsidiados para produção ou exportação.

Dessa forma, apesar de as tarifas nos países em desenvolvimento serem, em geral, mais elevadas do que as dos países desenvolvidos, na prática, as barreiras comerciais impostas pelo segundo grupo de países são significativamente superiores, dadas as barreiras não-tarifárias. Além disso, os países desenvolvidos têm inserção importante no mercado internacional, em virtude dos subsídios concedidos à produção e à exportação, o que limita a capacidade exportadora dos países do MERCOSUL.

Nesse contexto, uma das possibilidades existentes para ampliar o acesso ou até mesmo buscar novos mercados passa pela adesão dos países do MERCOSUL aos acordos de livre comércio, atualmente em discussão, cujos impactos (ganhos ou perdas) dependem do caráter do acordo regional ou multilateral.

Em termos multilaterais, há o acordo comercial em negociação junto à Organização Mundial do Comércio (OMC), a exemplo da Rodada Doha, que é exemplo de iniciativa que busca estimular a liberalização do comércio entre os países-membros. Nesta esfera de negociações estão sendo 
tratados, basicamente, temas relativos ao acesso a mercados (barreiras tarifárias e não-tarifárias), regulamentação e redução nos subsídios concedidos à produção e à exportação, que distorcem os preços agrícolas internacionais. Entretanto, o setor agrícola está entre os mais sensíveis às negociações. As dificuldades estão associadas, em grande parte, às especificidades da atividade agrícola e às diferenças econômicas marcantes entre os países envolvidos no processo de negociação. Entre outros aspectos, destacam-se a proteção do setor pelos países desenvolvidos, com argumentos de segurança alimentar e preservação do meio ambiente, por meio da associação de políticas comerciais e ambientais. Por parte de um grupo de países em desenvolvimento há justificativa de uma proteção seletiva, por meio da imposição de barreiras comerciais que permitam desenvolver setores agrícolas frágeis.

Dadas as dificuldades das negociações multilaterais, inúmeros acordos regionais vêm sendo firmados ou ampliados. O número de acordos entre países que formam blocos regionais cresceu substancialmente desde o início da década de 90 , e, até o final de 2005, haviam sido notificados à OMC, aproximadamente, 300 acordos.

Entre os acordos de livre comércio de caráter regional, em negociação pelos países do MERCOSUL, está o acordo com a União Européia (UE), que tem sido apontado, por diversos pesquisadores brasileiros, como o de maior potencial de ganhos para o setor agrícola dos países do Cone Sul. São salientadas também as dificuldades para implementar este acordo, principalmente em razão da proteção auferida pelos agricultores europeus, imposta pela Política Agrícola Comum (PAC) da EU, e das distorções geradas nos mercados de produtos agrícolas.

Paralelamente, há discussões acerca da formação da Área de Livre Comércio das Américas (ALCA), que envolve um processo de liberalização do comércio entre os países das Américas (com exceção de Cuba). Destaca-se a possibilidade de os países em desenvolvimento obterem ganhos com a liberalização do mercado do continente, principalmente devido ao potencial de incrementos nas exportações do 
setor. Isso acontece porque até mesmo os países relativamente mais industrializados, como o Brasil e a Argentina, ainda têm na agricultura o carro-chefe dos superávits da balança comercial. Entretanto, a região caracteriza-se por grandes assimetrias estruturais, acentuadas por distintas formas de conduzir políticas, que tendem a dificultar o processo de integração.

A maior dificuldade de negociação dos acordos de livre comércio, de caráter regional (MERCOSUL-UE e ALCA), está relacionada com a questão dos subsídios concedidos pelos países desenvolvidos, especificamente pelos EUA e pelos países da UE, que insistem que o debate sobre este tema deva ser conduzido no âmbito da OMC. Em outras palavras, em ambos os cenários de integração regional há o risco de os países desenvolvidos manterem ou até mesmo aumentarem a concessão de subsídios, ampliando as suas vantagens competitivas em relação aos países do MERCOSUL, em um cenário de menores barreiras comerciais.

Assim, este trabalho busca verificar os efeitos dos acordos de livre comércio multilaterais e regionais sobre o setor de carne bovina nos países do MERCOSUL. Com base na simulação de novos cenários de livre comércio, é possível verificar quais os impactos na produção, no consumo e nos níveis de bem-estar e identificar quais as melhores posições adotadas pelos produtores de carne bovina do MERCOSUL em frente às negociações de livre comércio que estão sendo definidas junto à OMC e aos governos americanos e europeus. A análise de cenários futuros permite também avaliar os ganhos agregados por país ou região e verificar se o acordo é vantajoso para os produtores e para a sociedade como um todo.

A seguir, na seção 2 deste trabalho, é detalhado o modelo de equilíbrio espacial na forma de um Problema de Complementaridade Mista. Nesta seção, definem-se também as fontes e os tratamentos aos dados utilizados na projeção do cenário-base e na simulação dos cenários alternativos. Na seção 3, são discutidos os principais resultados obtidos a partir da 
simulação dos cenários alternativos para as diversas regiões de estudo. Ao final, são feitas as considerações finais e as sugestões de estratégias a serem adotadas pelo setor produtivo de carne bovina nos países do MERCOSUL.

\section{Metodologia}

O modelo de otimização, descrito nesta seção, utiliza uma formulação apresentada na forma de um Problema de Complementaridade Mista (PCM), conforme proposto por Thore (1992), Rutheford (1995) e Bishop, Nicholson e Pratt (2001) e já utilizado por Alvim (2003) e Alvim e Waquil (2005). É um modelo estático de equilíbrio espacial que pressupõe produtos homogêneos e considera a tecnologia, as preferências e o crescimento populacional como variáveis exógenas.

O modelo leva em consideração as funções de oferta e demanda de cada produto em cada região, os custos de transporte e a presença de barreiras ao comércio, conduzindo à estimação das quantidades produzidas e consumidas, dos fluxos comerciais e dos níveis de preços em equilíbrio. Com estes resultados, podem-se estimar os níveis de bemestar, medidos pelo excedente do produtor (EP) e excedente do consumidor (EC), bem como as variações ocorridas a partir de diferentes cenários simulados, o que permite a avaliação dos ganhos ou perdas em cada situação.

O PCM consiste em um sistema de equações simultâneas (lineares ou não), apresentadas na forma de desigualdades, as quais são derivadas a partir das funções de oferta e demanda dos produtos considerados em cada uma das regiões analisadas. O PCM é equivalente às condições de Kuhn-Tucker, de maximização da função Net Social Payoff ${ }^{3}$ (NSP), as quais são necessárias e suficientes para atingir um ponto de máximo do

Samuelson (1952) mostrou que o equilíbrio de mercado pode ser alcançado a partir da maximização da função de Net Social Payoff (NSP), obtida pela soma dos excedentes dos produtores e dos consumidores, conforme resgatado em Waquil (1995) e Alvim e Waquil (2004). 
valor da função NSP, o que, por sua vez, implica a obtenção do equilíbrio em todos os mercados e em todas as regiões. Entretanto, o PCM tem a vantagem de permitir a incorporação de tarifas, quotas-tarifárias e subsídios, com mais facilidade, no modelo.

O Quadro 1 apresenta a notação utilizada e a definição das variáveis para implementação do modelo. O conjunto das equações apresentadas, logo a seguir, corresponde ao PCM e representa as condições que permitem obter os preços (preço-sombra), as quantidades produzidas e consumidas e os fluxos comerciais entre as regiões, levando em consideração as tarifas, as quotas-tarifárias e os subsídios implementados nos mercados.

Quadro 1 - Variáveis utilizadas no modelo

\begin{tabular}{ll}
\hline$q_{j}^{d}$ & Quantidade demandada na região $\mathrm{j}$ \\
\hline$q_{i}^{s}$ & Quantidade ofertada na região i \\
\hline$X_{i, j}$ & fluxo de comércio entre a região i e a região $\mathrm{j}$ \\
\hline$t_{i, j}$ & custo de transporte da região i para a região $\mathrm{j}$ \\
\hline$S_{i}$ & subsídio concedido na região i \\
\hline $\operatorname{tar}_{i, j}$ & tarifa imposta sobre o produto originário da região i, na região j \\
\hline$q r_{i, j}$ & tarifa aplicada quando o fluxo exceder a quota tarifária $\left(Q_{i, j}\right)$ \\
\hline$\varphi_{i}$ & Multiplicador de Lagrange: preço-sombra na região produtora i \\
\hline$\lambda_{j}$ & Multiplicador de Lagrange: preço-sombra na região consumidora $\mathrm{j}$ \\
\hline
\end{tabular}

Fonte: organizado pelos autores. 


$$
\begin{array}{ll}
\varphi_{i} \geq 0, & \left(\sum_{j}^{J} X_{i, j}-q_{i}^{s}\right) \cdot \varphi_{i}=0, \forall i, j \\
\lambda_{j} \geq 0, & \left(q_{j}^{d}-\sum_{i}^{I} X_{i, j}\right) \cdot \lambda_{j}=0, \forall i, j \\
X_{i, j} \geq 0, \quad & \left(\lambda_{j}-\left(\varphi_{i}-S_{i}+t_{i, j}\right) \cdot\left(1+t a r_{i, j}+q r_{i, j}\right)\right) \cdot X_{i, j}=0, \forall i, j \\
q r_{i, j} \geq 0, \quad & \left(Q_{i, j}-X_{i, j}\right) \cdot q r_{i, j}=0, \forall i, j
\end{array}
$$

Considerando a primeira equação, observa-se que $j_{i}$ é uma variável complementar à expressão que restringe a soma das exportações da $i$ ésima região ao total produzido naquela região $i$ e representa o preçosombra na região produtora $t$. Em outras palavras, sempre que o preçosombra associado à produção daquele bem na região $i$ for maior que zero, o termo entre parênteses na equação (1) deverá ser, necessariamente, igual a zero, o que implica que a soma dos fluxos da região $\iota$ para todas as regiões (inclusive para ela própria, ou seja, produção para consumo na região mais as exportações) deverá ser igual à quantidade produzida na região.

Da mesma forma, a segunda equação apresenta uma variável $\lambda$, que é complementar à expressão que restringe a soma das importações da $j$ ésima região ao total consumido naquela região $j$, e representa o preçosombra na região consumidora $j$. Neste caso, sempre que o preço-sombra associado ao consumo daquele bem na região $j$ for maior que zero, o termo entre parênteses na equação (2) deverá ser, necessariamente, igual a zero, o que implica que a quantidade consumida na região $j$ deverá ser igual à soma dos fluxos para a região $j$ oriundas de todas as regiões (inclusive dela própria, ou seja, consumo originado de produção própria na região, mais as importações). 
As equações (3) e (4) determinam os fluxos comerciais entre as regiões, associando aos diferenciais de preços e levando em consideração os custos de transporte, subsídios, tarifas e quotas-tarifárias. Estas equações (3) e (4) implicam, no caso em que os fluxos comerciais de determinada região $i$ para uma região $j$ forem maiores do que zero, porém inferiores à quota estabelecida pela região $j\left(Q_{i, j}\right)$, que o preço do produto na região consumidora $j$ será resultado da combinação do preço na região produtora $i$, dos subsídios concedidos, dos custos de transporte da região $i$ para $j \mathrm{e}$ da tarifa imposta sobre as importações originárias da região $i$. Em contrapartida, no caso em que as importações da região $j$ forem iguais à quota determinada para a região, então o preço do produto na região j dependerá também da tarifa excedente $q r_{i, j}$, além do preço, dos custos de transporte e da tarifa de importação.

A seguir, são descritos os dados necessários e as fontes usadas na operacionalização do modelo. Os preços dos produtos e as quantidades produzidas e consumidas, utilizados na estimação das funções de oferta e demanda que geram as equações (1) e (2), foram obtidos do banco de dados da FAO, utilizando a média dos três últimos anos. A justificativa para utilizar a média de três anos é a redução nos efeitos de alterações eventuais nos níveis dessas variáveis, causadas por choques ou mudanças abruptas na economia, por eventos climáticos ou por outras variáveis que afetam a produção, o consumo e os preços ocasionalmente. Para estimar estas funções, também são necessárias as elasticidades-preço da oferta e da demanda em cada região considerada, as quais foram obtidas a partir do trabalho de Sullivan et al. (1992).

O Quadro 2 apresenta as treze regiões definidas neste estudo para implementar o modelo. Em geral, foram consideradas regiões que compreendem os atuais blocos regionais de maior importância, resultantes de acordos comerciais. Em alguns casos, entretanto, foram considerados alguns países isolados, em razão da dimensão do mercado e da nãoparticipação em blocos regionais. 
Os custos de transporte de carne bovina congelada, entre as regiões em estudo, foram calculados com base no custo de transporte de uma tonelada via marítima (US\$/milhas marítimas), obtidos a partir do USDA (2005) e das distâncias entre os países/regiões em estudo (milhas marítimas). Já as tarifas ad valorem sobre as importações, quotas-tarifárias e subsídios concedidos foram obtidas do banco de dados da UNCTAD. Como nem sempre os valores são comuns a todos os países pertencentes às regiões definidas neste estudo, foram utilizadas as tarifas médias dos países importadores dos blocos ou das regiões escolhidas.

Quadro 2 - Regiões consideradas no modelo

\begin{tabular}{|c|c|}
\hline Regiões & Definição \\
\hline AFR & África: compreende todos os países do continente africano \\
\hline ASE & $\begin{array}{l}\text { Association of South East Asian Nations (ASEAN): Brunei, Camboja, } \\
\text { Cingapura, Filipinas, Indonésia, Laos, Malásia, Mianmar, Tailândia e } \\
\text { Vietnã }\end{array}$ \\
\hline CAN & $\begin{array}{l}\text { Comunidade Andina de Nações (CAN): Bolívia, Colômbia, Equador, } \\
\text { Peru e Venezuela }\end{array}$ \\
\hline $\mathrm{CHI}$ & China \\
\hline JAP & Japão \\
\hline MER & $\begin{array}{l}\text { Mercado Comum do Sul (MERCOSUL): Argentina, Brasil, Paraguai e } \\
\text { Uruguai }\end{array}$ \\
\hline NAF & $\begin{array}{l}\text { North American Free Trade Agreement (NAFTA): Canadá, Estados } \\
\text { Unidos e México }\end{array}$ \\
\hline OCE & Oceania \\
\hline OME & Oriente Médio \\
\hline $\mathrm{RM}$ & $\begin{array}{l}\text { Resto do Mundo: compreende os demais países não incorporados em } \\
\text { nenhuma das regiões consideradas }\end{array}$ \\
\hline RUS & Rússia \\
\hline SAP & $\begin{array}{l}\text { South Asian Preferential Trade Agreement (SAPTA): Bangladesh, } \\
\text { Butan, Índia, Maldivas, Nepal, Paquistão, Sri Lanka }\end{array}$ \\
\hline UE25 & $\begin{array}{l}\text { União Européia: Alemanha, Áustria, Bélgica, Dinamarca, Espanha, } \\
\text { Finlândia, França, Grécia, Holanda, Irlanda, Itália, Luxemburgo, } \\
\text { Portugal, Reino Unido e Suécia, mais os dez novos membros } \\
\text { incorporados ao bloco em 2004: Chipre, Eslováquia, Eslovênia, } \\
\text { Estônia, Hungria, Letônia, Lituânia, Malta, Polônia e República Tcheca }\end{array}$ \\
\hline
\end{tabular}

Fonte: organizado pelos autores. 
A partir da obtenção dos resultados do modelo aplicado no cenário base, foi feita a calibragem para ajustar à situação atual. Posteriormente, quatro cenários foram simulados, removendo barreiras ao comércio, com vistas em possibilitar a verificação dos impactos nas quantidades, nos preços e nos níveis de bem-estar. Tais cenários estão no Quadro 3, a seguir.

\begin{tabular}{ll} 
Quadro 3 - Cenários considerados \\
\hline Cenário & Definição \\
\hline 1 & $\begin{array}{l}\text { Acordo multilateral - livre comércio com manutenção } \\
\text { de subsídios }\end{array}$ \\
\hline 2 & $\begin{array}{l}\text { Acordo multilateral - livre comércio com retirada de } \\
\text { subsídios }\end{array}$ \\
\hline 3 & Acordo bi-regional entre o MERCOSUL e a EU \\
\hline 4 & $\begin{array}{l}\text { Acordo regional que forma a Área de Livre Comércio } \\
\text { das Américas (ALCA) }\end{array}$
\end{tabular}

Fonte: organizado pelos autores.

\section{Resultados}

A literatura sobre o comércio internacional discute a possibilidade de os efeitos estáticos e dinâmicos, associados aos processos de integração entre países, envolverem a remoção de barreiras ao comércio. Os efeitos estáticos estão, de modo geral, relacionados com conceitos de criação e desvio de comércio, podendo provocar ganhos ou perdas de bem-estar aos agentes envolvidos, enquanto os efeitos dinâmicos são decorrentes do aumento em concorrência, economias de escala, estímulo aos investimentos e aumento da produtividade dos fatores.

Pelos resultados discutidos a seguir, baseados num modelo estático de alocação espacial (com funções de oferta e demanda fixas, estimadas a partir das quantidades, preços e elasticidades conforme apontado na seção anterior), consideram-se apenas os efeitos estáticos dos processos de integração, nos níveis multilateral e regional. Não se ignora, no entanto, a 
possibilidade de ocorrência, nem se menospreza a importância dos efeitos dinâmicos. Em outros artigos, tais efeitos foram considerados quando se analisaram as vantagens comparativas reveladas e os índices de orientação regional das exportações de diversos produtos agrícolas, ao longo do tempo, em diferentes cenários de integração entre os países (Barbosa e Waquil, 2001; Waquil, Alvim, Silva e Trapp, 2004).

Outro aspecto importante a comentar é a inclusão no modelo das barreiras tarifárias, quotas e subsídios praticados em cada região. Dado o caráter específico que assumem as barreiras sanitárias, podem ser incluídas no modelo na forma de proibições. São elas que, atualmente, mais influenciam os fluxos comerciais, em vista do recente surgimento de focos de Encefalia Espongiforme Bovina (EEB, vulgarmente conhecida como Mal da Vaca Louca) e de febre aftosa.

A Tabela 1 apresenta os resultados encontrados para o cenário base, após a calibragem do modelo. Dentre as treze regiões consideradas, apenas em três concentraram-se $57,6 \%$ da produção de carne bovina. De um total produzido em todas as regiões, que correspondia a 57,249 milhões de toneladas por ano, os países do NAFTA produziam 25,6\%; o MERCOSUL, 17,7\%; e a EU, 14,3\%. Estas regiões são também as que apresentaram os níveis mais elevados de consumo, e são justamente as principais regiões envolvidas no desenho dos cenários 3 e 4 , que caracterizam os processos de integração regional.

Com relação aos excedentes gerados (produção menos consumo, que corresponde a um déficit quando o resultado for negativo), observa-se, na Tabela 1, que apenas quatro regiões tiveram valores positivos Oceania, Mercosul, SAPTA e Comunidade Andina de Nações (CAN), o que os caracteriza como potenciais exportadoras. Do total estimado de fluxos comerciais de carne bovina entre as regiões (3,066 milhões de toneladas - convém observar que aqui não estão computados os fluxos intra-regionais, o que implica uma soma significativamente menor que o total do comércio internacional de carne bovina), a Oceania foi responsável por mais da metade, 57,7\%, e o MERCOSUL alcançou outros $36,8 \%$ das exportações, configurando-se como as duas grandes regiões exportadoras. 
Duas outras regiões tiveram excedentes nulos, visto que igualaram produção e consumo, quais sejam, a UE (apesar de caracterizar-se como uma das regiões maiores produtoras) e a definida, aqui, como o Resto do Mundo (RM). Nas demais regiões foram obtidos valores negativos, que caracterizam déficits de produção com relação ao consumo. No caso da China, o valor foi pequeno, mas cresceu (em valor absoluto) nas regiões da África, ASEAN, Oriente Médio, Japão e Rússia e NAFTA. É importante observar que o NAFTA, apesar de ser a maior produtora, foi também a maior importadora de carne bovina, dentre as regiões caracterizadas neste estudo.

Tabela 1 - Produção, consumo, excedente do produtor (EP) e do consumidor (EC) no cenário-base do mercado de carne bovina

\begin{tabular}{|c|c|c|c|c|c|c|}
\hline Países / & Produção & Consumo & Excedente & EP & EC & EP+EC \\
\hline Regiões & $\begin{array}{c}\text { (mil } \\
\text { toneladas) }\end{array}$ & $\begin{array}{c}\text { (mil } \\
\text { toneladas) }\end{array}$ & $\begin{array}{c}\text { (mil } \\
\text { toneladas) }\end{array}$ & $\begin{array}{c}\text { (US\$ } \\
\text { milhões) }\end{array}$ & $\begin{array}{c}\text { (US\$ } \\
\text { milhões) }\end{array}$ & $\begin{array}{c}\text { (US\$ } \\
\text { milhões) }\end{array}$ \\
\hline AFR & $3.016,8$ & $3.134,8$ & $-118,0$ & $5.827,3$ & $5.778,1$ & $11.605,4$ \\
\hline ASE & $1.057,9$ & $1.210,1$ & $-152,2$ & $3.622,1$ & $3.762,6$ & $7.384,8$ \\
\hline $\mathrm{CAN}$ & $1.874,3$ & $1.859,6$ & 14,7 & $2.513,6$ & $1.434,5$ & $3.948,1$ \\
\hline $\mathrm{CHI}$ & $5.566,6$ & $5.574,1$ & $-7,5$ & $27.685,7$ & $7.128,6$ & $34.814,2$ \\
\hline $\mathrm{JAP}$ & 503,6 & $1.231,6$ & $-728,0$ & $1.671,0$ & $1.560,1$ & $3.231,1$ \\
\hline MER & $10.127,9$ & $8.999,0$ & $1.128,9$ & $15.214,4$ & $9.776,0$ & $24.990,5$ \\
\hline NAF & $14.643,5$ & $15.678,5$ & $-1.035,0$ & $25.958,6$ & $26.790,2$ & $52.748,8$ \\
\hline OCE & $2.794,4$ & $1.026,1$ & $1.768,4$ & $3.095,6$ & 949,3 & $4.044,9$ \\
\hline $\mathrm{OME}$ & $1.885,3$ & $2.165,4$ & $-280,1$ & $9.077,3$ & $7.257,9$ & $16.335,2$ \\
\hline $\mathrm{RM}$ & $3.636,9$ & $3.636,9$ & 0,0 & $9.157,1$ & $4.845,2$ & $14.002,2$ \\
\hline RUS & $1.861,3$ & $2.606,7$ & $-745,4$ & $7.018,3$ & $13.834,2$ & $20.852,5$ \\
\hline SAP & $2.081,7$ & $1.927,4$ & 154,4 & $9.868,5$ & $9.751,6$ & $19.620,1$ \\
\hline UE25 & $8.199,2$ & $8.199,2$ & 0,0 & $19.080,8$ & $15.230,1$ & $34.310,9$ \\
\hline
\end{tabular}

Fonte: resultados obtidos pelos autores.

As três últimas colunas da Tabela 1 apresentam as medidas do excedente do produtor (EP) e do excedente do consumidor (EC), em milhões de dólares, calculadas após a estimação das quantidades ofertadas e 
demandadas, assim como dos níveis de preços (preços-sombra). Tais medidas serão utilizadas na avaliação dos impactos nos diferentes cenários, por meio do cálculo das variações resultantes da remoção das barreiras ao comércio.

As demais tabelas ilustram os efeitos dos acordos comerciais (multilaterais e regionais), simulados neste estudo, sobre os níveis de produção (Tabela 2), excedente do produtor (Tabela 3 ) e a soma do excedente do produtor e do excedente do consumidor (Tabela 4), tanto em termos absolutos (mil toneladas ou milhões de dólares) como em termos relativos (\%) (Tabelas 2, 3 e 4).

Os resultados mostram, em todos os cenários, ganhos mais acentuados nos países do MERCOSUL. Considerando-se a produção de carne bovina, nas Tabelas 2 e 3 notam-se também significativos aumentos na produção e no excedente do produtor nas regiões da Oceania e da Comunidade Andina de Nações (CAN), em razão dos diferenciais de preços com as demais regiões e da simulação da remoção de barreiras ao comércio.

Nos primeiros dois cenários, que envolvem um acordo multilateral com manutenção ou remoção de subsídios, as variações na produção de carne bovina nestas três regiões (MERCOSUL, Oceania e CAN) seriam de 13,5 a 16,7\% (Tabela 2). Com a liberalização comercial, a produção de carne bovina no MERCOSUL aumentaria, aproximadamente, 1,4 milhão de toneladas, gerando um incremento no excedente de 4,6 a 4,8 bilhões de dólares para o produtor (Tabela 3). Mesmo se houvesse redução no excedente do consumidor, gerada pelo aumento nos preços e pela diminuição no consumo (em vista do aumento nas exportações), o nível de bem-estar agregado (medido pela soma das variações no excedente do produtor e excedente do consumidor) teria o maior resultado positivo no MERCOSUL (Tabela 4).

Tanto na Oceania como na CAN, o incremento na produção superaria 300 mil toneladas de carne bovina (Tabela 2), o que corresponderia a um aumento de quase 1 milhão de dólares no excedente do produtor (Tabela 3). No entanto, as regiões que mais perderiam nestes cenários seriam o 
NAFTA e a UE. Nos países do NAFTA, a redução na produção, caso o acordo multilateral removesse barreiras ao comércio, chegaria a quase 1 milhão de toneladas (Tabela 2), ocasionando uma redução superior a 3,2 bilhões de dólares no excedente do produtor (Tabela 3). Tais perdas seriam compensadas por ganhos no excedente do consumidor, gerados pela queda nos preços e pelo aumento no consumo (em vista do aumento nas importações), resultando em valor positivo da variação no nível de bem-estar agregado (Tabela 4).

É importante notar que, nas regiões exportadoras, o efeito da remoção dos subsídios (Cenário 2) seria pequeno, se comparado ao da liberalização sem remoção de subsídios (Cenário 1). O efeito seria substancial apenas no caso da UE, como esperado, no qual as variações na produção e nos excedentes do produtor se alterariam significativamente. No cenário 1 , a redução na produção de carne bovina na UE foi estimada em 551,6 mil toneladas, causada pela abertura do acesso aos mercados, mas passaria para 932,6 mil, no cenário 2, com a eliminação dos subsídios à produção e exportação (Tabela 2). A perda de excedente do produtor, na EU, alcançaria quase 2,5 bilhões de dólares no Cenário 1, e superaria os 4,0 bilhões de dólares, no Cenário 2 (Tabela 3). No Cenário 2, os ganhos dos consumidores (medidos pela variação no excedente do consumidor) não chegariam a ser suficientes para compensar as perdas dos produtores, resultando ainda numa perda de 1,2 bilhão de dólares no nível de bemestar agregado (Tabela 4). 
Tabela 2 - Variações na produção com relação ao cenário-base do mercado de carne bovina

\begin{tabular}{|c|c|c|c|c|c|c|c|c|}
\hline \multirow{2}{*}{$\begin{array}{l}\text { Países / } \\
\text { Regiões }\end{array}$} & \multicolumn{4}{|c|}{$\begin{array}{l}\text { Variação na produção } \\
\text { (mil toneladas) }\end{array}$} & \multicolumn{4}{|c|}{$\begin{array}{l}\text { Variação na produção } \\
(\%)\end{array}$} \\
\hline & Cenário 1 & Cenário 2 & Cenário 3 & Cenário 4 & Cenário 1 & Cenário 2 & Cenário 3 & Cenário 4 \\
\hline AFR & 82,4 & 92,0 & 56,2 & 56,2 & $2,7 \%$ & $3,1 \%$ & $1,9 \%$ & $1,9 \%$ \\
\hline ASE & $-40,5$ & $-38,6$ & 6,8 & $-5,0$ & $-3,8 \%$ & $-3,6 \%$ & $0,6 \%$ & $-0,5 \%$ \\
\hline$\overline{\mathrm{CAN}}$ & 303,9 & 313,9 & 109,9 & 250,8 & $16,2 \%$ & $16,7 \%$ & $5,9 \%$ & $13,4 \%$ \\
\hline$\overline{\mathrm{CHI}}$ & $-57,6$ & $-50,5$ & 1,6 & $-11,5$ & $-1,0 \%$ & $-0,9 \%$ & $0,0 \%$ & $-0,2 \%$ \\
\hline JAP & $-57,1$ & $-55,9$ & 4,3 & $-3,1$ & $-11,3 \%$ & $-11,1 \%$ & $0,8 \%$ & $-0,6 \%$ \\
\hline$\overline{\text { MER }}$ & $1.398,3$ & $1.448,0$ & 687,5 & $1.136,1$ & $13,8 \%$ & $14,3 \%$ & $6,8 \%$ & $11,2 \%$ \\
\hline NAF & $-966,9$ & $-981,1$ & 187,5 & $-1.345,9$ & $-6,6 \%$ & $-6,7 \%$ & $1,3 \%$ & $-9,2 \%$ \\
\hline$\overline{\mathrm{OCE}}$ & 377,6 & 392,4 & 44,8 & $-32,8$ & $13,5 \%$ & $14,0 \%$ & $1,6 \%$ & $-1,2 \%$ \\
\hline$\overline{\mathrm{OME}}$ & $-32,5$ & $-30,1$ & 29,4 & 15,7 & $-1,7 \%$ & $-1,6 \%$ & $1,6 \%$ & $0,8 \%$ \\
\hline RM & $-59,6$ & $-50,7$ & 0,0 & 0,0 & $-1,6 \%$ & $-1,4 \%$ & $0,0 \%$ & $0,0 \%$ \\
\hline RUS & 112,9 & 115,8 & 44,6 & 28,1 & $6,1 \%$ & $6,2 \%$ & $2,4 \%$ & $1,5 \%$ \\
\hline$\overline{\text { SAP }}$ & 92,4 & 95,0 & 29,6 & 14,9 & $4,4 \%$ & $4,6 \%$ & $1,4 \%$ & $0,7 \%$ \\
\hline UE25 & $-551,6$ & $-932,6$ & $-986,5$ & 0,0 & $-6,7 \%$ & $-11,4 \%$ & $-12,0 \%$ & $0,0 \%$ \\
\hline
\end{tabular}

Fonte: resultados obtidos pelos autores.

Nos Cenários 3 e 4, que envolvem a integração entre regiões selecionadas, conforme as negociações em andamento, os resultados mudariam sensivelmente. No caso de um acordo entre o MERCOSUL e a UE, simulado no Cenário 3, o incremento na produção de carne bovina, nos países do MERCOSUL, poderia atingir 687,5 mil toneladas, representando uma variação de $6,8 \%$ (Tabela 2). Este incremento, como resposta aos ajustes nos preços praticados nos diferentes mercados, geraria uma variação no excedente do produtor de quase 2,2 bilhões de dólares (Tabela $3)$. Novamente, apesar da redução no excedente do consumidor causada por redução no consumo e aumento no preço, o bem-estar agregado aumentaria (Tabela 4). Entretanto, convém notar que todos os ganhos, nos países do MERCOSUL (aumento na produção, no excedente do produtor ou no bem-estar agregado), seriam os menores encontrados entre os quatro cenários trabalhados. 
Em contrapartida, as variações encontradas, nos países que compõem a EU, seriam as maiores, entre os quatro cenários, e justamente no sentido contrário. Na simulação de um acordo entre o MERCOSUL e a UE, as perdas para os produtores de carne bovina no bloco europeu poderiam alcançar 986,5 mil toneladas, representando uma redução de 12,0\% na produção (Tabela 2), o que acabaria gerando um decréscimo de mais de 4,2 bilhões de dólares no excedente do produtor (Tabela 3). Tais perdas seriam compensadas por ganhos auferidos pelos consumidores europeus, em vista da queda nos preços e aumento no consumo, resultando numa variação no nível de bem-estar agregado, que superaria 1,4 bilhão de dólares (Tabela 4). Este é um argumento importante para facilitar o acordo entre os blocos, considerando que tais compensações pudessem ser repassadas aos produtores.

Nas demais regiões consideradas no modelo, não envolvidas diretamente no acordo simulado no Cenário 3, que reduz as barreiras entre o MERCOSUL e a UE, as variações seriam menores, resultantes dos ajustamentos nos níveis de preços e nos fluxos comerciais. Vale a pena comentar que, dado o acordo entre os dois blocos, o MERCOSUL redirecionou suas exportações para a Europa, abrindo mão de outros mercados; em conseqüência, a Comunidade Andina (CAN) e o NAFTA aumentaram a produção, ainda que em percentuais bem inferiores às variações nos outros cenários. 
Tabela 3 - Variações no excedente do produtor (“EP) com relação ao cenário-base do mercado de carne bovina

\begin{tabular}{|c|c|c|c|c|c|c|c|c|}
\hline \multirow{2}{*}{$\begin{array}{l}\text { Países / } \\
\text { Regiões }\end{array}$} & \multicolumn{4}{|c|}{$\begin{array}{l}\text { Variação no excedente do produtor } \\
\text { (US\$ milhões) }\end{array}$} & \multicolumn{4}{|c|}{$\begin{array}{l}\text { Variação no excedente do produtor } \\
(\%)\end{array}$} \\
\hline & Cenário 1 & Cenário 2 & Cenário 3 & Cenário 4 & Cenário 1 & Cenário 2 & Cenário 3 & Cenário 4 \\
\hline AFR & 322,4 & 361,0 & 218,5 & 218,5 & $5,5 \%$ & $6,2 \%$ & $3,7 \%$ & $3,7 \%$ \\
\hline ASE & $-279,8$ & $-267,1$ & 49,1 & $-35,7$ & $-7,7 \%$ & $-7,4 \%$ & $1,4 \%$ & $-1,0 \%$ \\
\hline CAN & 924,8 & 959,0 & 311,2 & 748,6 & $36,8 \%$ & $38,2 \%$ & $12,4 \%$ & $29,8 \%$ \\
\hline $\mathrm{CHI}$ & $-569,2$ & $-499,5$ & 15,6 & $-114,9$ & $-2,1 \%$ & $-1,8 \%$ & $0,1 \%$ & $-0,4 \%$ \\
\hline JAP & $-346,2$ & $-340,1$ & 28,9 & $-21,0$ & $-20,7 \%$ & $-20,4 \%$ & $1,7 \%$ & $-1,3 \%$ \\
\hline MER & $4.643,1$ & $4.825,4$ & $2.167,2$ & $3.700,9$ & $30,5 \%$ & $31,7 \%$ & $14,2 \%$ & $24,3 \%$ \\
\hline NAF & $-3.273,0$ & $-3.318,9$ & 667,4 & $-4.480,7$ & $-12,6 \%$ & $-12,8 \%$ & $2,6 \%$ & $-17,3 \%$ \\
\hline$\overline{\mathrm{OCE}}$ & 913,5 & 952,1 & 100,9 & $-72,6$ & $29,5 \%$ & $30,8 \%$ & $3,3 \%$ & $-2,3 \%$ \\
\hline OME & $-322,4$ & $-299,7$ & 307,0 & 161,9 & $-3,6 \%$ & $-3,3 \%$ & $3,4 \%$ & $1,8 \%$ \\
\hline $\mathrm{RM}$ & $-301,8$ & $-257,3$ & 0,0 & 0,0 & $-3,3 \%$ & $-2,8 \%$ & $0,0 \%$ & $0,0 \%$ \\
\hline$\overline{\text { RUS }}$ & 861,1 & 885,2 & 325,5 & 203,0 & $12,3 \%$ & $12,6 \%$ & $4,6 \%$ & $2,9 \%$ \\
\hline SAP & 870,4 & 897,2 & 267,0 & 132,7 & $8,8 \%$ & $9,1 \%$ & $2,7 \%$ & $1,3 \%$ \\
\hline UE25 & $-2.466,5$ & $-4.032,7$ & $-4.245,8$ & 0,0 & $-12,9 \%$ & $-21,1 \%$ & $-22,3 \%$ & $0,0 \%$ \\
\hline
\end{tabular}

Fonte: resultados obtidos pelos autores.

Por fim, no Cenário 4, no qual é simulada a formação da ALCA, a produção de carne bovina nos países do MERCOSUL voltaria a crescer, podendo alcançar um incremento de mais de 1,1 milhão de toneladas, uma variação de $11,2 \%$ (Tabela 2). Os países da CAN também teriam ganhos de produção, alcançando uma variação de mais de 250 mil toneladas de carne bovina, o que corresponderia a uma variação de $13,4 \%$ no valor encontrado no cenário- base. Como esperado, os países do NAFTA teriam as maiores perdas. Com a liberalização do comércio nas Américas, a produção de carne bovina nos países da América do Norte poderia diminuir em mais de 1,3 milhão de toneladas ou 9,2\% da quantidade estimada no cenário- base. As variações nos níveis de produção de carne bovina, nas demais regiões definidas neste estudo, seriam pequenas.

Neste cenário, as variações no bem-estar dos produtores de carne bovina, medidas pelas variações no excedente do produtor, resultariam dos ajustes nas quantidades produzidas e nos preços praticados. Conforme os 
resultados apresentados na Tabela 3, tais variações no excedente do produtor corresponderiam a, respectivamente, um ganho de 3,7 bilhões de dólares no MERCOSUL e de quase 750 milhões de dólares na CAN (Tabela 3). Novamente, a única região que apresentaria perda mais elevada seria o NAFTA, cujo valor atingiria, aproximadamente, 4,5 bilhões de dólares.

Tabela 4 - Variações no excedente do produtor e do consumidor (“EP+”EC), com relação ao cenário-base, do mercado de carne bovina

\begin{tabular}{|c|c|c|c|c|c|c|c|c|}
\hline Países / & $\begin{array}{l}\text { Variação I } \\
\text { consumido }\end{array}$ & $\begin{array}{l}\text { no exceder } \\
\text { lor (US\$ mi }\end{array}$ & $\begin{array}{l}\text { nte do pro } \\
\text { ilhões) }\end{array}$ & & $\begin{array}{c}\text { doVariação } \\
\text { consumid } \\
\end{array}$ & $\begin{array}{l}\text { no excede } \\
\text { lor }(\%)\end{array}$ & te do & odutor e do \\
\hline Regiões & Cenário 1 & Cenário 2 & Cenário 3 & Cenário & 4 Cenário 1 & Cenário 2 & Cenário 3 & Cenário 4 \\
\hline AFR & $-3,7$ & $-2,4$ & $-5,5$ & $-5,5$ & $0,0 \%$ & $0,0 \%$ & $0,0 \%$ & $0,0 \%$ \\
\hline$\overline{\mathrm{ASE}}$ & 44,5 & 41,7 & $-4,1$ & 3,6 & $0,6 \%$ & $0,6 \%$ & $-0,1 \%$ & $0,0 \%$ \\
\hline CAN & 271,0 & 287,3 & 46,1 & 192,4 & $6,9 \%$ & $7,3 \%$ & $1,2 \%$ & $4,9 \%$ \\
\hline$\overline{\mathrm{CHI}}$ & 16,6 & 12,1 & 0,2 & $-0,2$ & $0,0 \%$ & $0,0 \%$ & $0,0 \%$ & $0,0 \%$ \\
\hline JAP & 785,5 & 764,5 & $-38,6$ & 30,0 & $24,3 \%$ & $23,7 \%$ & $-1,2 \%$ & $0,9 \%$ \\
\hline MER & $1.367,7$ & $1.448,7$ & 447,4 & 976,0 & $5,5 \%$ & $5,8 \%$ & $1,8 \%$ & $3,9 \%$ \\
\hline NAF & 716,8 & 354,9 & $-49,6$ & $1.222,7$ & $1,4 \%$ & $0,7 \%$ & $-0,1 \%$ & $2,3 \%$ \\
\hline$\overline{\mathrm{OCE}}$ & 649,4 & 678,9 & 66,0 & $-46,4$ & $16,1 \%$ & $16,8 \%$ & $1,6 \%$ & $-1,1 \%$ \\
\hline OME & 46,3 & 42,3 & $-24,5$ & $-15,2$ & $0,3 \%$ & $0,3 \%$ & $-0,1 \%$ & $-0,1 \%$ \\
\hline $\mathrm{RM}$ & $-0,9$ & $-2,0$ & 0,0 & 0,0 & $0,0 \%$ & $0,0 \%$ & $0,0 \%$ & $0,0 \%$ \\
\hline RUS & $-294,1$ & $-299,9$ & $-132,6$ & $-86,0$ & $-1,4 \%$ & $-1,4 \%$ & $-0,6 \%$ & $-0,4 \%$ \\
\hline SAP & 88,9 & 93,2 & 16,3 & 6,8 & $0,5 \%$ & $0,5 \%$ & $0,1 \%$ & $0,0 \%$ \\
\hline UE25 & 490,0 & $-1.253,4$ & $1.419,0$ & 0,0 & $1,4 \%$ & $-3,7 \%$ & $4,1 \%$ & $0,0 \%$ \\
\hline
\end{tabular}

Fonte: resultados obtidos pelos autores.

Assim como no cenário anterior, no qual os consumidores europeus obtiveram ganhos mais do que compensavam as perdas dos produtores, agora eram os consumidores dos países do NAFTA que auferiam ganhos gerados pela redução nos preços praticados e pelo aumento no consumo, permitindo compensações aos produtores que tiveram perdas. No caso de um acordo comercial nas Américas, formando a ALCA, o bem-estar agregado aumentaria 1,2 bilhão de dólares no NAFTA; 976 milhões no MERCOSUL; e 192 milhões de dólares na CAN (Tabela 4). Mediante compensações, o acordo poderia trazer ganhos ao setor produtivo na região. 


\section{Considerações finais}

O artigo compreende a quantificação e a análise dos efeitos de quatro cenários de integração regional e liberalização comercial sobre o setor de carne bovina. Para isto, foi utilizado um modelo de alocação espacial, estático, formulado como um Problema de Complementaridade Mista (PCM), levando em consideração treze regiões, o qual permite a mensuração das variações na produção, no consumo e nos preços-sombra, em vista da remoção de barreiras ao comércio, assim como a estimação das variações resultantes nos níveis de bem-estar, por meio das variações no excedente do produtor e excedente do comsumidor.

Esta é uma das contribuições do trabalho; a modelagem e a simulação de cenários. O modelo pode ser utilizado para analisar os efeitos de outros cenários que sejam de interesse dos tomadores de decisão, bem como para analisar os efeitos em outros setores produtivos. Constitui, desta forma, uma importante ferramenta para auxiliar o processo de tomada de decisão quanto às negociações em andamento, por meio da estimação dos ganhos ou perdas associados a cada setor, em cada possível cenário de integração entre países ou regiões.

No caso analisado no presente artigo, os resultados apontam ganhos para o setor produtivo de carne bovina do MERCOSUL, em todos os cenários considerados. Estes ganhos seriam maiores nos cenários de integração multilateral (com manutenção ou com remoção de subsídios), mas também seriam substanciais nos cenários de acordos regionais que abrangessem a formação da ALCA e um acordo entre o MERCOSUL e a UE. A ampliação dos mercados, atualmente já alcançada, e a abertura de novos mercados possibilitariam a expansão das exportações de carne bovina por parte dos países do MERCOSUL, levando ao aumento na produção e nos preços, o que acabaria gerando um incremento no bemestar. Outras regiões que também auferiram ganhos foram a Oceania e a Comunidade Andina de Nações (CAN). 
Como esperado, principalmente nos países que compõem o NAFTA e a EU, haveria possibilidades de perdas para os produtores de carne bovina, a partir da remoção de barreiras ao comércio que estas regiões impõem. Entretanto, em geral, tais perdas poderiam ser compensadas pelos ganhos auferidos pelos consumidores, em vista da redução nos preços e no aumento no consumo. Mediante essas compensações, a liberalização comercial poderia trazer benefícios a todos os agentes envolvidos nos processos de integração entre os países e, ou, regiões. Desta forma, os países do MERCOSUL teriam nestes resultados mais um argumento nas negociações para redução no protecionismo no setor agrícola por parte dos países desenvolvidos.

Finalmente, é fundamental que seja dada atenção especial às questões referentes à sanidade dos rebanhos, assim como a outras questões técnicas, uma vez que as barreiras sanitárias e técnicas têm tido papel relevante na definição dos fluxos comerciais entre os países. Os ganhos aqui estimados, resultantes dos acordos comerciais simulados em quatro cenários, somente poderão ser obtidos se controlados os focos de febre aftosa, o que permitiria a consolidação dos mercados para a exportação da carne bovina proveniente dos países do MERCOSUL.

\section{Referências}

ALVIM, A. M. Os impactos dos acordos de livre comércio sobre o mercado de arroz no Brasil: um modelo de alocação espacial e temporal. Porto Alegre: PPGE/UFRGS, 2003. (Tese de Doutorado).

ALVIM, A. M. e WAQUIL P. D. "O problema de complementaridade mista: um modelo de alocação espacial aplicado ao setor agrícola". In: Santos, M. L. e Vieira, W. C. Métodos quantitativos em economia. Viçosa, MG: UFV, 2004, p. 161-190. 
ALVIM, A. M. e WAQUIL, P. D. "O acordo entre o Mercosul e a União Européia: efeitos sobre os mercados de grãos". In: XLIII Congresso Brasileiro de Economia e Sociologia Rural. Anais ... Ribeirão Preto, SP: SOBER, 2005.

BARBOSA, A. E. e WAQUIL, P. D. "O rumo das exportações agrícolas brasileiras frente às negociações para a formação da Área de Livre Comércio das Américas (ALCA)". Indicadores Econômicos FEE, Porto Alegre, v.29, n.3, p.70-85, nov./2001.

BISHOP, P.M.; NICHOLSON, C.F. e Pratt, J.E. Tariff-rate quotas: difficult to model or plain simple. Wellington: NZIER, 2001. Paper presented at the annual conference of the New Zealand Agricultural and Resource Economics Society. Disponível em: http://www.nzier.co.nz. Acesso em 15/dez/02.

MIRANDA, S. H. G. Quantificação dos efeitos das barreiras nãotarifárias sobre as exportações brasileiras de carne bovina. Piracicaba, SP: ESALQ/USP, 2001. (Tese de Doutorado).

RUBIN, L. S. O comércio brasileiro de carnes no contexto da integração regional. Santa Maria, RS: MILA/UFSM, 2005. (Dissertação de Mestrado).

RUTHEFORD, T. F. "Extension of GAMS for complementarity problems arising in applied economic analysis". Journal of Economics Dynamics \& Control, v.19, p. 1299-1324, 1995.

SAMUELSON, P. "Spatial price equilibrium and linear programming". American Economic Review, v. 42, p. 283-303, 1952.

SULLIVAN, J. et al. 1989 global database for the Static World Policy Simulation (SWOPSIM) modeling framework. Washington, D.C.: USDA/ERS, Staff Report n. AGES 9215, 1992. 
THORE, S. Economic logistics: the optimization of spatial and sectoral resource, production and distribution systems. New York: Westport: London: Quorum Books, 1992.

UNCTAD (United Nation Conference on Trade and Development). UNCTAD -Trains (Trade Analysis and Information System), 2005. Disponível em: http://www.unctad.org. Acesso: 20/nov./05.

USDA Ocean Rate Bulletin. March 31, 2005. Disponível em: http:// www.ams.usda.gov. Acesso: 15/nov/2005.

\section{WAQUIL, P. D. Primal-dual spatial equilibrium model with} intermediate products: an application to the agricultural sector in the MERCOSUR. Madison, WI: University of Wisconsin, 1995 (Ph.D. Thesis)

WAQUIL, P. D.; ALVIM, A. M.; SILVA, L. X. e TRAPP, G. P. "Vantagens comparativas reveladas e orientação regional das exportações agrícolas brasileiras para a União Européia". In: XLII Congresso Brasileiro de Economia e Sociologia Rural. Anais ... Cuiabá, MT: SOBER, 2004.

Abstract - This study identifies the effects of free trade agreements at the multilateral (WTO) and regional (FTAA and MERCOSUR-EU) levels on the bovine meat markets in several regions. In order to evaluate these effects, we used a spatial allocation model, presented as a mixed complementarity problem (MCP). The study identifies the changes in production and consumption levels, as well as the changes in producer and consumer surplus, in four possible scenarios. In general, gains to bovine meat producers in the MERCOSUR countries are expected in all scenarios. Although, these gains are greater when we simulate a multilateral trade liberalization, with or without the elimination of subsidies.

Keywords: free trade; regional integration; mixed complementarity problem; bovine meat. 
REVISTA DE ECONOMIA E AGRONEGÓCIO, VOL.4, $N^{\circ} 2$ 